\title{
Research on the Fracture Properties and Modification Mechanism of Polyester Fiber and SBR Latex Modified Cement Concrete
}

\author{
Mingkai Zhou, ${ }^{1}$ Dong Fang, ${ }^{1}$ and Deyong Jiang ${ }^{2}$ \\ ${ }^{1}$ State Key Laboratory of Silicate Building Materials, Wuhan University of Technology, Wuhan 430070, China \\ ${ }^{2}$ Guizhou Building Material Quality Supervision Testing Center, Guiyang 550002, China
}

Correspondence should be addressed to Dong Fang; 479461118@qq.com

Received 16 November 2015; Accepted 19 April 2016

Academic Editor: Wei Liu

Copyright (C) 2016 Mingkai Zhou et al. This is an open access article distributed under the Creative Commons Attribution License, which permits unrestricted use, distribution, and reproduction in any medium, provided the original work is properly cited.

\begin{abstract}
Polyester fiber and SBR latex cement concrete is prepared as pavement surface material; its fracture properties including fracture toughness, fracture energy, CMOD, and flexural strength are studied comparing with those of normal concrete (NC), polyester fiber modified concrete (FMC), SBR polymer modified concrete (SMC), and the combination of polyester fiber and SBR polymer modified concrete (FSMC). The modification mechanism of the latex and fiber on the concrete was also studied by the methods including X-ray test, chemically combined water, heat of hydration, water loss, and scanning electron microscope. Results indicated that the concrete modified by latex and polyester fiber has flexural strength, fracture toughness, and fracture energy of $44.4 \%$, $397.0 \%$, and $462.8 \%$ higher than the reference normal concrete, the polymer retarded the hydration process and reduced the hydration degree of cement at early age, while the hydration degree is promoted by the polymer film for its excellent water resistance after $28 \mathrm{~d}$, and the bond between the fiber and cement paste is improved by the latex.
\end{abstract}

\section{Introduction}

Polymer latex and polyester fiber have been already widely applied in the modified cement mortar. Different kinds of polymer latex and fiber have different effect on the mechanical properties of the material. From the researches in recent years, styrene-butadiene rubber (SBR) latex has excellent mechanical properties, flow ability, and impermeability to make better modification on the cement mortar and cement concrete [1-3]. The flexural strength, working performance, and durability of the concrete modified by the polymer have greatly improved except resistance to sulfuric acid [4-6]. The fiber can also improve the resistance of the concrete cracking. Most of the research show that adding $90 \mathrm{~kg} / \mathrm{m}^{3}$ SBR latex, the flexural strength of cement concrete increased about $20 \%$, but its compressive strength reduced about $5 \%$ $[7,8]$. The polymer modification is mainly on the fracture or flexural properties of the material. The polyester fiber can also improve the mechanical properties including flexural strength especial. The SBR latex may have some chemical reaction with the $\mathrm{Ca}(\mathrm{OH})_{2}$ generated by the hydration of cement [9], but the content of SBR latex is usually too small comparing with the content of cement and aggregates. The mechanical property is mainly affected by the hydration of cement. On account of research background represented above, the fracture properties including flexural strength, fracture toughness, fracture energy, and crack mouth opening displacement (CMOD) of normal concrete (NC), SBR latex modified concrete (SMC), polyester fiber modified concrete (FMC), and the combination of polyester fiber and SBR latex modified concrete (FSMC) are compared in this paper. The modification mechanism of polymer latex on the cement hydration and polyester fiber enhancement has also been studied.

\section{Experimental Methods and Raw Material}

SBR latex and polyester fiber modified cement concrete mainly consist of the cement, sand, stone, and water like the normal concrete, and the analysis of its fracture process 
TABLE 1: The main properties of SBR latex.

\begin{tabular}{|c|c|c|c|c|c|c|}
\hline Solid content (\%) & $\mathrm{pH}$ & Viscosity at $25^{\circ} \mathrm{C}(\mathrm{mPa} \cdot \mathrm{s})$ & Density $\left(\mathrm{g} / \mathrm{cm}^{3}\right)$ & Average particle diameter $(\mathrm{nm})$ & Surface tension $(\mathrm{mN} / \mathrm{m})$ & $T_{g}\left({ }^{\circ} \mathrm{C}\right)$ \\
\hline $50 \sim 52$ & 8.1 & $35 \sim 150$ & 1.01 & 150 & $30 \sim 48$ & 13 \\
\hline
\end{tabular}

TABLE 2: The main properties of polyester fiber.

\begin{tabular}{lcccc}
\hline Diameter $(\mathrm{mm})$ & Water content $(\%)$ & Breaking strength $(\mathrm{MPa})$ & Modulus of elasticity $(\mathrm{GPa})$ & Elongation $(\%)$ \\
\hline 0.08 & 0.70 & 2067 & 15090 & 18.36 \\
\hline
\end{tabular}

adopts the same method as the normal concrete. According to material fracture theory, the fracture toughness $K_{\text {IC }}$ reflects the ability of material to prevent the crack growth under the fracture lord. Fracture energy and crack mouth opening displacement of concrete can be considered closely related to the fracture process [10].

Fracture energy $G_{f}$ is an important fracture parameters of concrete; it is the energy consumed by the formation of fracture area under the load [11]. Concrete fracture test methods include wedge splitting and three-point bending method. Because the wedge splitting method has more strict requirement, the three-point bending method which RILEM recommended to analyze the fracture properties is adopted [12]. The fracture toughness $K_{\mathrm{IC}}$ is calculated using the equation

$$
K_{\mathrm{IC}}=\frac{P_{\text {VMAX }} S}{B H^{1.5}} f\left(\frac{a}{H}\right)
$$

in which

$$
\begin{aligned}
f\left(\frac{a}{H}\right)= & 2.9\left(\frac{a}{H}\right)^{0.5}-4.6\left(\frac{a}{H}\right)^{1.5}+21.8\left(\frac{a}{H}\right)^{2.5} \\
& -37.6\left(\frac{a}{H}\right)^{3.5}+38.7\left(\frac{a}{H}\right)^{4.5},
\end{aligned}
$$

where $P_{V M A X}$ is the measured maximum bending load (N). $S$ is the span (m). $H$ is the height of the specimen $(\mathrm{m}) . B$ is the width of the specimen $(\mathrm{m})$.

Fracture energy $G_{f}$ is calculated using the equation:

$$
G_{f}=\frac{1}{B(H-a)}\left[W_{0}+\left(m_{1}+2 m_{2}\right) g \delta_{\max }\right]
$$

where $m_{1}$ is the self-weight of the specimen between supports $(\mathrm{kg}) ; m_{2}$ is the weight of specimen fixture of machine $(\mathrm{kg}) ; W_{0}$ is the area under the load-deflection curve $(\mathrm{N} \cdot \mathrm{m}) ; \delta_{\max }$ is the maximum displacement $(\mathrm{m})$.

The XRD curves are analyzed by X-ray diffraction and the $d$ value, FWHM, $I_{\text {integ }}$, and $I_{\max }$ are gained by software of Jade 6.5. Heat process of cement hydration is analyzed by the heat meter where the type is TAM Air produced by the American TA company. The water loss of cement concrete is measured in the constant temperature and humidity box with the temperature at $25^{\circ} \mathrm{C}$ and the humidity at $65 \%$. The cement concrete specimens for scanning electron micrograph (SEM) testing are cured for $28 \mathrm{~d}$.

The main properties of SBR latex and polyester fiber are listed in Tables 1 and 2. An ordinary Portland cement which
TABLE 3: The mix proportion of four kinds of concrete.

\begin{tabular}{lccc}
\hline Sample & Type & $\begin{array}{c}\text { Polymer content } \\
\left(\mathrm{kg} / \mathrm{m}^{3}\right)\end{array}$ & $\begin{array}{c}\text { Polyester fiber } \\
\left(\mathrm{kg} / \mathrm{m}^{3}\right)\end{array}$ \\
\hline $1 \#$ & NC & 0 & 0 \\
$2 \#$ & SMC & 90 & 0 \\
$3 \#$ & FMC & 0 & 2.2 \\
$4 \#$ & FSMC & 90 & 2.2 \\
\hline
\end{tabular}

has $52.6 \mathrm{MPa}$ compressive strength at 28 days is used; its content in the concrete is $350 \mathrm{~kg} / \mathrm{m}^{3}$. Coarse aggregate with maximum size of $16 \mathrm{~mm}$ and sand are crushed limestone. Polycarboxylates high performance water-reducing admixture which has $28.1 \%$ water-reducing rate is incorporated in the concrete mixtures, and its content is $5.25 \mathrm{~kg} / \mathrm{m}^{3}$.

Four kinds of concrete are compared and the mix proportion of normal cement concrete, polymer modified cement concrete, polyester fiber modified cement concrete, and polymer and polyester fiber modified cement concrete are listed in Table 3.

\section{Results and Discussion}

3.1. Fracture Properties. The effect of polymer and polyester fiber on the strength and fracture properties of concrete is shown in Tables 4-7. The results illustrate that the SBR latex and polyester fiber both have improvement on the flexural strength, fracture toughness, fracture energy, and $\mathrm{CMOD}_{\max }$, but the levels of improvement are different. Comparing to the sample $1 \#$ of $\mathrm{NC}$, the flexural strength, fracture toughness, fracture energy, and $\mathrm{CMOD}_{\max }$ of sample $2 \#$ increased by $37.1 \%, 269.6 \%, 360.4 \%$, and $213.0 \%$, respectively; the corresponding dates for sample $3 \#$ are $8.4 \%, 41.5 \%, 91.7 \%$, and $54.3 \%$. The SBR latex has more significant effect on the properties of the concrete than the polyester fiber. For sample $4 \#$ with the cement concrete modified by the SBR latex and polyester fiber, the properties mentioned above have further improvement. The coefficients of variance of samples $2 \#$ and 3\# modified by SBR latex are smaller than sample 1\#, so the latex and fiber both can improve the homogeneity of concrete. The SBR latex and polyester fiber have combined enhancement for the fracture properties of concrete, but the modification on fracture toughness and fracture energy is more significant than the flexural strength.

But the compressive strength of samples $2 \#$ and $3 \#$ is less than sample $1 \#$, so the addition of both SBR latex and 
TABLE 4: The test results of sample $1 \#$ of NC concrete at the age of $28 \mathrm{~d}$.

\begin{tabular}{lccccc}
\hline 1 \# specimens & Flexural strength $(\mathrm{MPa})$ & Compressive strength $(\mathrm{MPa})$ & $K_{\mathrm{IC}}(\mathrm{MPa} \sqrt{\mathrm{m}})$ & $G_{f}(\mathrm{~N} / \mathrm{m})$ & $\mathrm{CMOD}$ \\
\hline 1 & 5.49 & 53.6 & 1.32 & 140 & 0.43 \\
2 & 5.55 & 54 & 1.34 & 169 & 0.45 \\
3 & 5.7 & 55.2 & 1.39 & 175 & 0.51 \\
Average & 5.58 & 54.3 & 1.35 & 161.33 & 0.46 \\
Coefficient of variance & $1.9 \%$ & $1.5 \%$ & $2.7 \%$ & $11.6 \%$ & $9.0 \%$ \\
\hline
\end{tabular}

TABLE 5: The test results of sample 2\# of SMC at the age of $28 \mathrm{~d}$.

\begin{tabular}{lccccc}
\hline 2\# specimens & Flexural strength $(\mathrm{MPa})$ & Compressive strength $(\mathrm{MPa})$ & $K_{\mathrm{IC}}(\mathrm{MPa} \sqrt{\mathrm{m}})$ & $G_{f}(\mathrm{~N} / \mathrm{m})$ & $\mathrm{CMOD}$ \\
\hline 1 & 7.59 & 50.8 & 4.56 & 722.11 & 1.36 \\
2 & 7.66 & 51.9 & 5.11 & 755.76 & 1.41 \\
3 & 7.69 & 52.7 & 5.3 & 757.38 & 1.55 \\
Average & 7.65 & 51.8 & 4.99 & 745.08 & 1.44 \\
Coefficient of variance & $0.7 \%$ & $1.8 \%$ & $7.7 \%$ & $2.7 \%$ & $6.8 \%$ \\
\hline
\end{tabular}

TABLE 6: The test results of sample 3\# of FMC at the age of $28 \mathrm{~d}$.

\begin{tabular}{lccccc}
\hline 3\# specimens & Flexural strength $(\mathrm{MPa})$ & Compressive strength $(\mathrm{MPa})$ & $K_{\mathrm{IC}}(\mathrm{MPa} \sqrt{\mathrm{m}})$ & $G_{f}(\mathrm{~N} / \mathrm{m})$ & $\mathrm{CMOD}$ max \\
\hline 1 & 5.95 & 46.1 & 1.76 & 299.87 \\
2 & 6.09 & 48.9 & 1.87 & 311.45 & 0.65 \\
3 & 6.11 & 50.4 & 2.1 & 319.36 & 0.73 \\
Average & 6.05 & 48.5 & 1.91 & 310.23 & 0.76 \\
Coefficient of variance & $1.4 \%$ & $4.5 \%$ & $9.1 \%$ & $3.2 \%$ & $8.0 \%$ \\
\hline
\end{tabular}

TABLE 7: The test results of sample $4 \#$ of FSMC at the age of $28 \mathrm{~d}$.

\begin{tabular}{lccccc}
\hline 4\# specimens & Flexural strength $(\mathrm{MPa})$ & Compressive strength $(\mathrm{MPa})$ & $K_{\mathrm{IC}}(\mathrm{MPa} \sqrt{\mathrm{m}})$ & $G_{f}(\mathrm{~N} / \mathrm{m})$ & $\mathrm{CMOD}$ \\
\hline 1 & 7.95 & 45.5 & 6.62 & 897.35 & 1.54 \\
2 & 8.03 & 45.7 & 6.73 & 916.29 \\
3 & 8.21 & 46.4 & 6.79 & 918.46 \\
Average & 8.06 & 45.9 & 6.71 & 910.70 & 1.62 \\
Coefficient of variance & $1.7 \%$ & $1.0 \%$ & $1.3 \%$ & 1.68 \\
\hline
\end{tabular}

polyester fiber has the negative effect on the compressive strength of concrete.

The curves of three-point bending tests results of the four kinds of concrete are plotted in Figure 1. The slope from sample $1 \#$ of $\mathrm{NC}$ is higher than the others. After the flexural load reaches the peak value, it drops suddenly. Sample 1\# exhibits typical brittle fracture characteristics. The slope gets lower and the peak becomes gentle from the curve of sample 3\#. The modification by the fiber decreases the elastic modulus of concrete, but the modification by the latex is more evident.

The slope becomes lower and there is more obvious plastic change process showed in the curve of sample 2\#. There are many original defects, cracks inside the hardened concrete. After the concrete reaches the limit, the microcracks inside the concrete start to grow. Polymer films and fibers both have effect of bridge conjunction on weakening the growth of cracks. The average grain diameter of SBR latex is $150 \mathrm{~nm}$, it is much smaller than the diameter of polyester fiber, and more cracks can be filled and bonded by the polymer films. So the effect of SBR latex is more evident. On the other hand, the peak value, max midspan displacement, and integral area of curve of sample $4 \#$ are higher than the others. Just before the bending load reaches the limit, the cracks get to expand from surface to inside. The fibers begin to draw out and break, at the same time the polymer films stuck to the cement or the aggregate also begin to tear and break. So it needs more energy when the cracks grow, making the fracture properties of sample 4\# improves significantly.

In order to investigate the modification mechanism of SBR latex and polyester fiber, the SBR film formation, cement hydration, and their interaction are first researched because it can be recognized that the polyester fiber is stable and has no chemical reaction with the cement and SBR latex.

3.2. Film Forming Process of SBR Latex by Optical Microscopic Test. Figure 2 shows the appearance of SBR latex film formation under the optical microscope. The SBR latex shows 


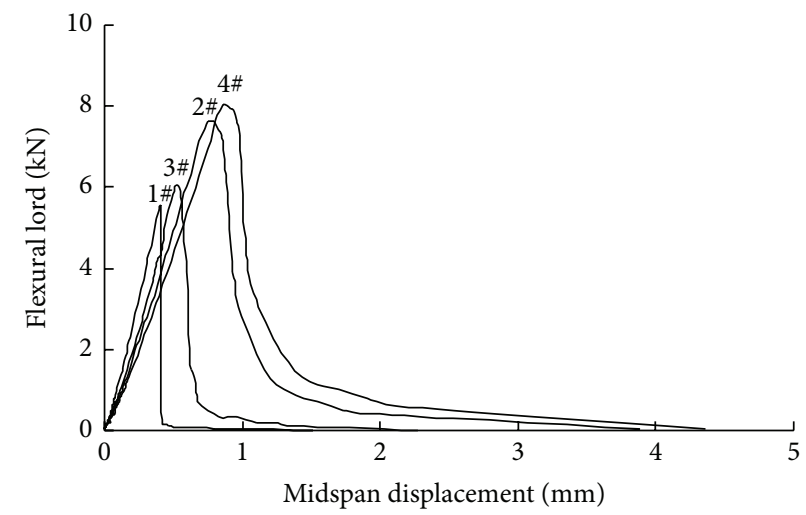

FIGURE 1: The comparison of load-displacement curve with different kinds of concrete.

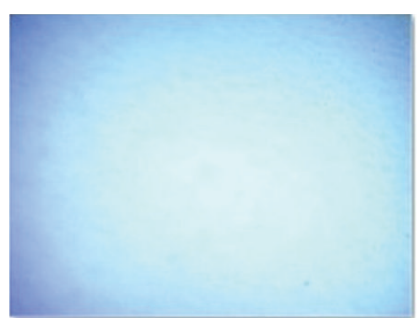

0 min

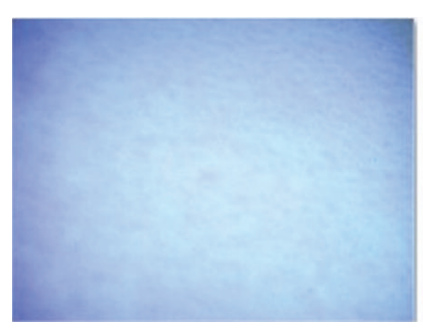

$105 \mathrm{~min}$

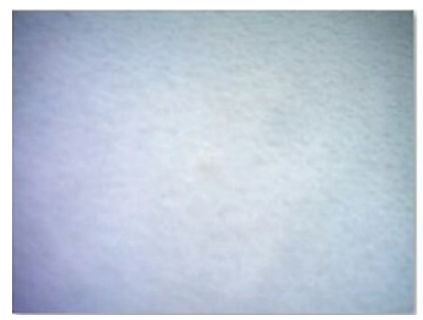

$150 \mathrm{~min}$

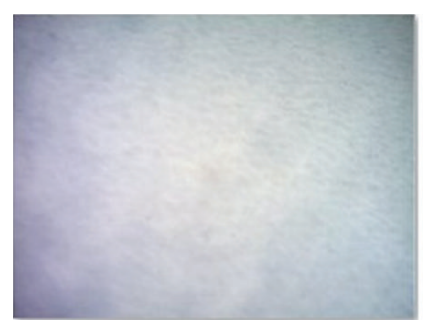

$200 \mathrm{~min}$

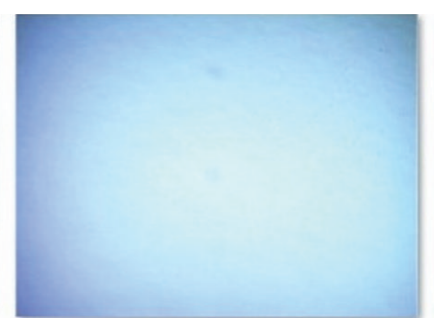

$30 \mathrm{~min}$

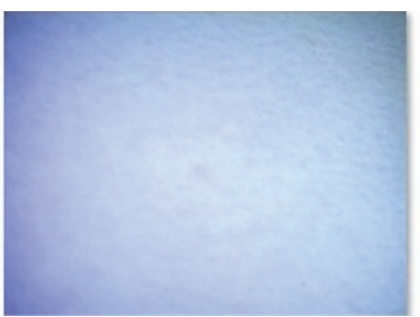

$120 \mathrm{~min}$

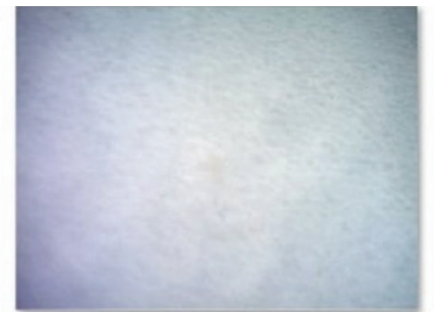

$160 \mathrm{~min}$

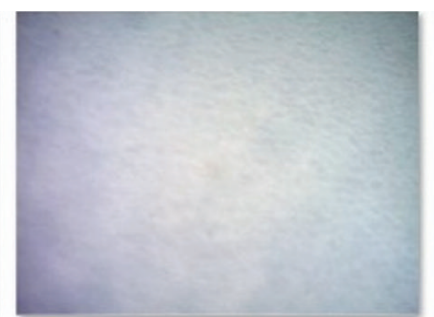

220 min

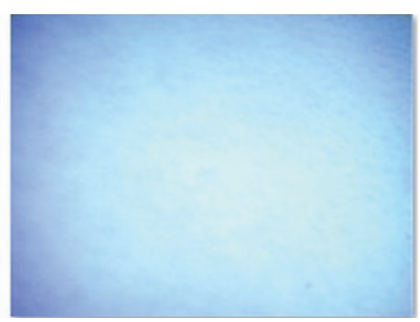

$60 \mathrm{~min}$

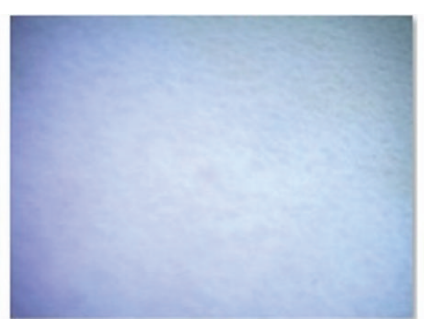

$130 \mathrm{~min}$

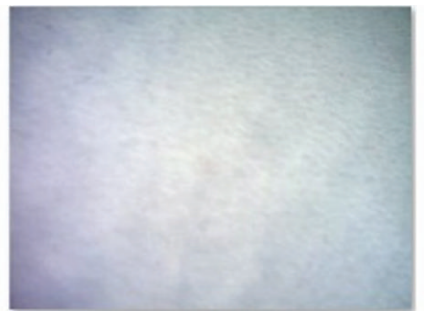

$170 \mathrm{~min}$

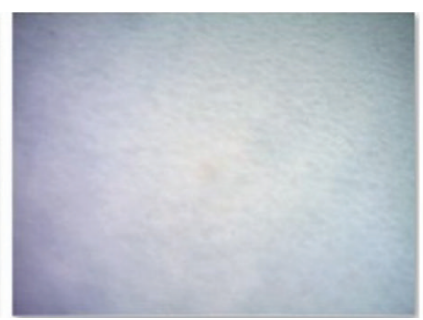

$240 \mathrm{~min}$

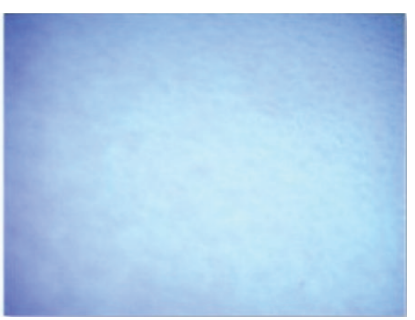

$90 \mathrm{~min}$

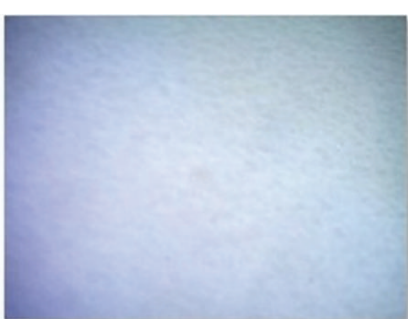

$140 \mathrm{~min}$

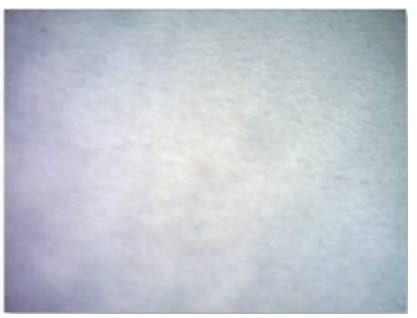

$185 \mathrm{~min}$

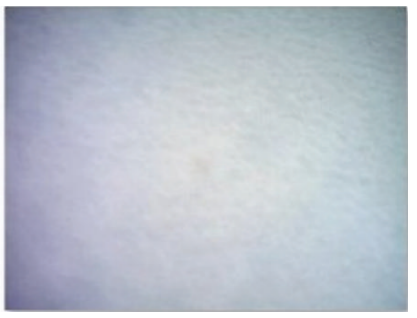

$300 \mathrm{~min}$

FIGURE 2: The color variance of polymer film forming process under the microscope. 


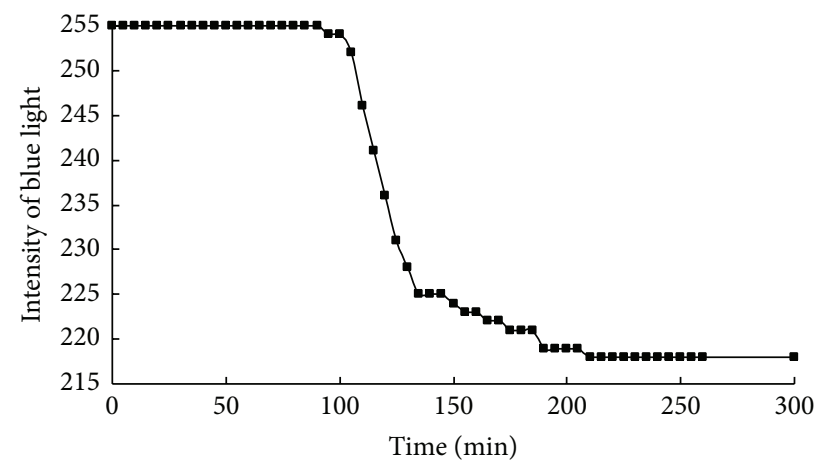

FIGURE 3: The intensity change of blue light at the formation of polymer film.

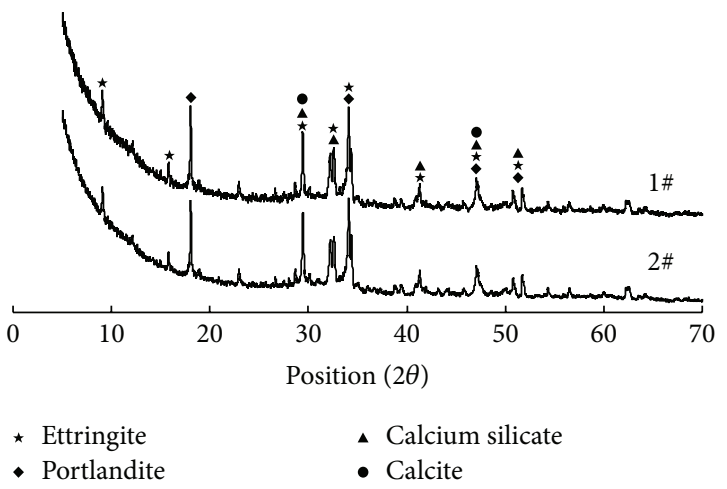

FIGURE 4: The comparison of XRD patterns of SBR latex modified cement paste and normal cement paste.

light blue because the polymer particles make the light which have longer wavelength scatter, and the blue light which has shorter wavelength can pass through. With the forming of the polymer particles in SBR latex, the intensity of light gets weak gradually, and the color of light becomes gray. Figure 3 illustrates the change of blue light with the time. After 200 minutes, the variation becomes stable, and the film formation gets finished. So it can be speculated that the processes of latex film formation are faster and earlier than the cement hydration.

3.3. X-Ray Test. Comparing the results of qualitative X-ray diffraction analysis at the age of $7 \mathrm{~d}$ from Figure 4, both are roughly similar in shape. So there is not any special chemical products found in the SMC, but the characteristics of peaks around 18 degrees corresponding to 001 crystal face of $\mathrm{Ca}(\mathrm{OH})_{2}$ are different. Table 8 shows the results at the age of $3 \mathrm{~d}, 7 \mathrm{~d}, 28 \mathrm{~d}$, and $90 \mathrm{~d}$.

At the age of $3 \mathrm{~d}$ and $7 \mathrm{~d}, I_{\text {integ }}$ and $I_{\max }$ of sample 2\# are both less than corresponding value of sample $1 \#$, but they increase and get higher at the age of $28 \mathrm{~d}$ and $90 \mathrm{~d}$. The results illustrate that the SBR latex retards the hydration of cement at early age, but it has the effect of promotion after the age of $28 \mathrm{~d}$.
TABLE 8: The characteristics of XRD diffraction peak at the angle of $17-19^{\circ}$ for cement pastes with different $\mathrm{P} / \mathrm{C}$.

\begin{tabular}{lccccc}
\hline Age & Sample & $\begin{array}{c}d \text { value } \\
(\mathrm{nm})\end{array}$ & $\begin{array}{c}\text { FWHM } \\
\left(^{\circ}\right)\end{array}$ & $\begin{array}{c}I_{\text {integ }} \\
(\text { counts })\end{array}$ & $\begin{array}{c}I_{\max } \\
(\text { counts })\end{array}$ \\
\hline \multirow{2}{*}{3} & $1 \#$ & 4.918 & 0.137 & 6245 & 1037 \\
& $2 \#$ & 4.913 & 0.129 & 4029 & 814 \\
\hline 7 & $1 \#$ & 4.915 & 0.175 & 7867 & 1590 \\
& $2 \#$ & 4.909 & 0.171 & 6158 & 1337 \\
\hline \multirow{2}{*}{28} & $1 \#$ & 4.910 & 0.178 & 8730 & 1864 \\
& $2 \#$ & 4.921 & 0.175 & 8842 & 1921 \\
\hline \multirow{2}{*}{90} & $1 \#$ & 4.911 & 0.181 & 9572 & 2137 \\
& $2 \#$ & 4.914 & 0.184 & 10573 & 2368 \\
\hline
\end{tabular}

TABLE 9: The influence of SBR latex on the chemically combined water content of SBR latex modified cement paste (\%).

\begin{tabular}{lcccc}
\hline Sample & $3 \mathrm{~d}$ & $7 \mathrm{~d}$ & $28 \mathrm{~d}$ & $90 \mathrm{~d}$ \\
\hline $1 \#$ & 18.21 & 22.08 & 26.94 & 27.84 \\
$2 \#$ & 16.89 & 20.96 & 27.27 & 28.16 \\
\hline
\end{tabular}

3.4. Chemically Combined Water. Table 9 shows the chemically combined water content at different ages. At the early age of $3 \mathrm{~d}$ and $7 \mathrm{~d}$, chemically combined water contents of sample $1 \#$ are higher than sample 2\#, but the corresponding values of sample 2\# become higher after $28 \mathrm{~d}$. Same as the results researched above, the SBR latex promotes the hydration at the later age.

3.5. Hydration Heat of Cement Paste. From the heat release curve of cement hydration showed in Figure 5, both have the evident periods of induction, acceleration, deceleration, and stability. The max value of heat liberation of sample $1 \#$ is $3.22 \mathrm{~mW} / \mathrm{g}$ at the time of $8.15 \mathrm{~h}$, and max value of heat liberation of sample 2\# is $2.87 \mathrm{~mW} / \mathrm{g}$ at the time of $9.11 \mathrm{~h}$. So the SBR latex not only can reduce the extent of the cement hydration but also delays the process at very early age.

3.6. Variation of Water Content Test for Concrete. Figure 6 shows the water loss of NC and SMC at age from $1 \mathrm{~d}$ to $180 \mathrm{~d}$. The water loss increases gradually as the time goes by, but it gradually becomes stable after $60 \mathrm{~d}$. In the whole period, the water loss of sample 1\# is higher than the other. At the age of $180 \mathrm{~d}$, the water loss of samples $1 \#$ and $2 \#$ is $0.97 \%$ and $0.73 \%$, and the water in polymer modified cement concrete is more stable. The polymer films were soaked in the water for $28 \mathrm{~d}$ and remain stable as shown in Figure 7. The polymer film has the excellent ability of waterproof, and it blocks the water inside the concrete and makes the weight stable. It can conclude that the stability of water content in SMC has positive effect on the hydration of cement.

3.7. Micromorphology by SEM Test. The microstructure images of SBR latex modified cement paste are shown in Figures 8-11 at different days. Because the SBR latex forming process is faster and earlier than the cement, the already 


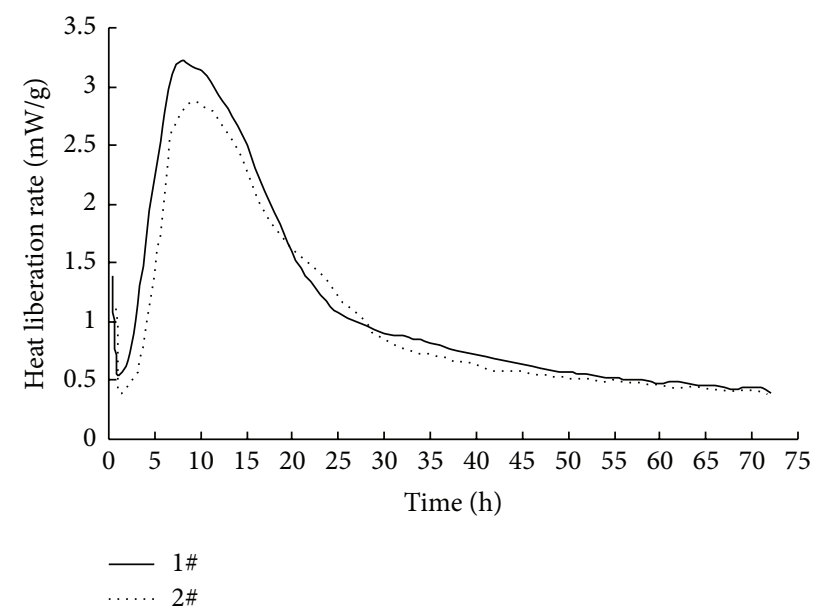

Figure 5: Comparison of heat liberation of cement hydration.

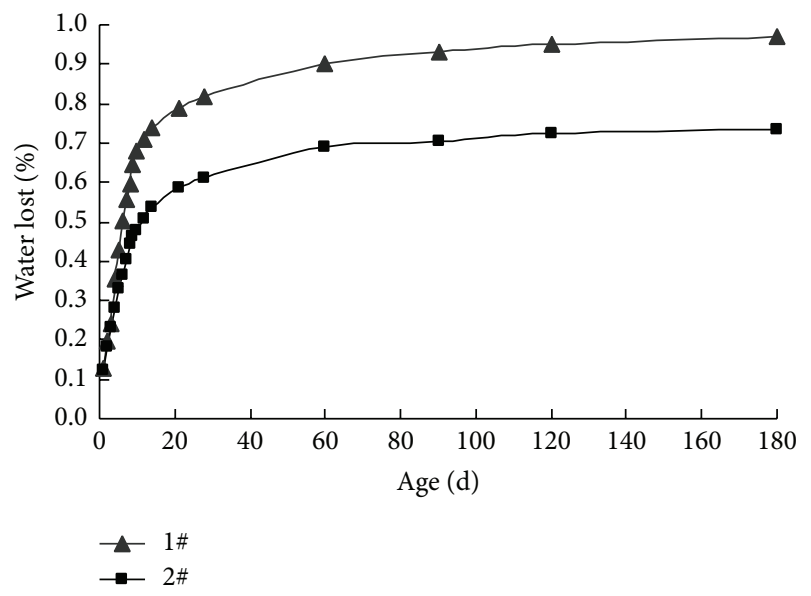

FIGURE 6: The comparison of water loss rate of SMC and NC.

formed polymer film covering on the surface of cement after 1 day can be seen in Figure 8. After 3 days the cement hydrates, and some hydration including ettringite and C-S$\mathrm{H}$ gel starts to grow and breaks through some polymer film. The phenomenon becomes more evident after $7 \mathrm{~d}$ and $28 \mathrm{~d}$.

Figure 12 shows the SEM image magnified by 200 times of fracture surface of FMC. As can be seen, with (1) 5 red circular region of obvious black holes, they can be judged as the voids left by the fibers at angle of big degree to the fracture surface draw out from the concrete. Under the flexural load, these fibers have the ability of strengthening the bounding power, hindering the development of cracks, and have positive effect on the fracture properties of normal cement concrete. (2) With 3 blue rectangular regions of black grooves, they are left by the fibers at angle of small degree to the fracture surface. These fibers can be recognized where they are much easier to pull out from the material than the fibers formerly described and they have small effect on the bonding strength. (3) One yellow rectangular region of fiber surrounded by a black ring remains on the fracture surface. Though these fibers are still left in the surface, the bound between it and the cement matrix is weak. (4) One green rectangular region of fiber is

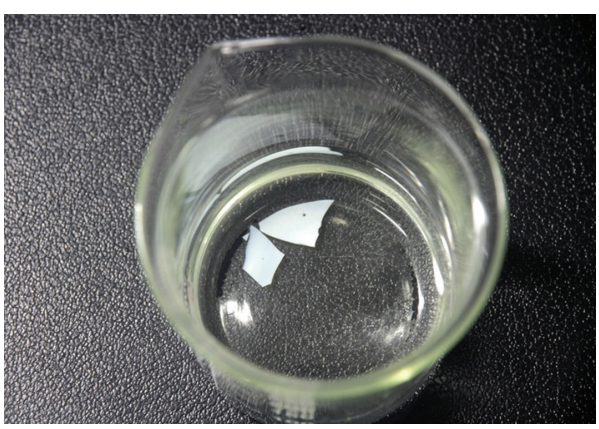

FIGURE 7: The polymer film formed by SBR latex and soaked in the water for 28 days.

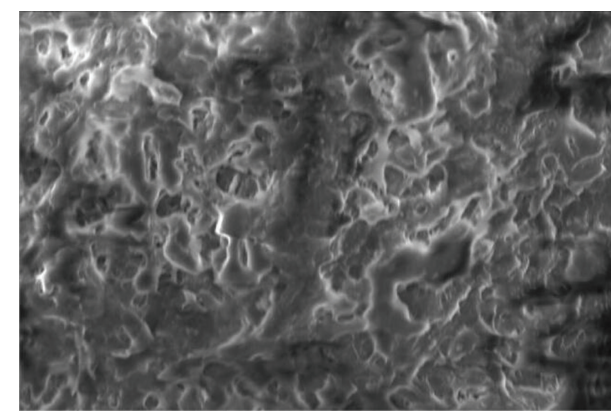

FIGURE 8: SEM image of SBR latex modified cement paste after 1 day $(\times 5000)$.

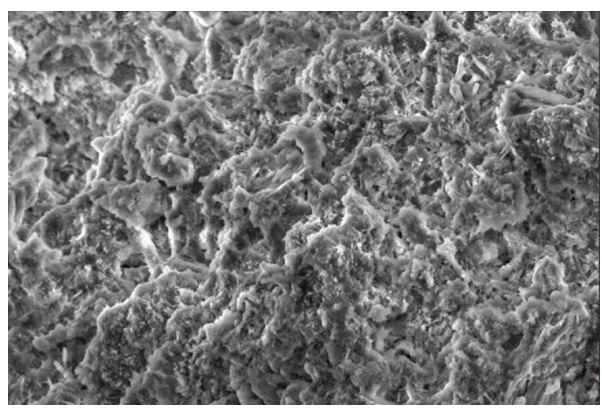

FIGURE 9: SEM image of SBR latex modified cement paste after 3 days $(\times 5000)$.

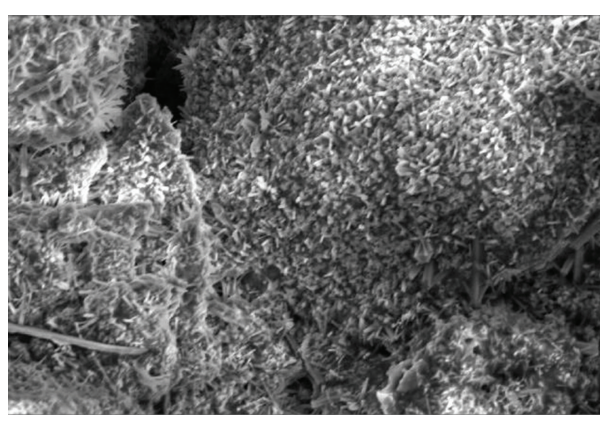

FIgURE 10: SEM image of SBR latex modified cement paste after 7 days $(\times 5000)$. 


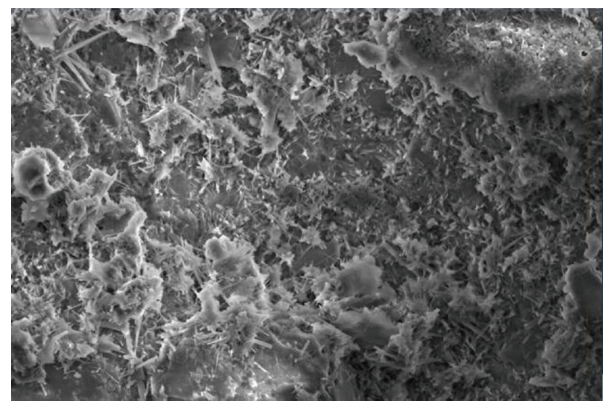

Figure 11: SEM image of SBR latex modified cement paste after 28 days $(\times 5000)$.

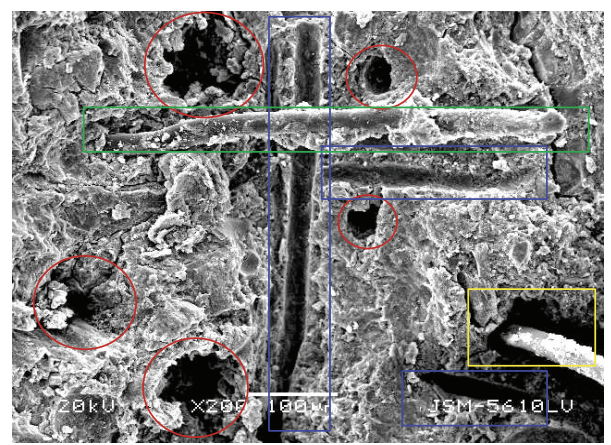

FIGURE 12: SEM image of fiber modified cement concrete $(\times 200)$.

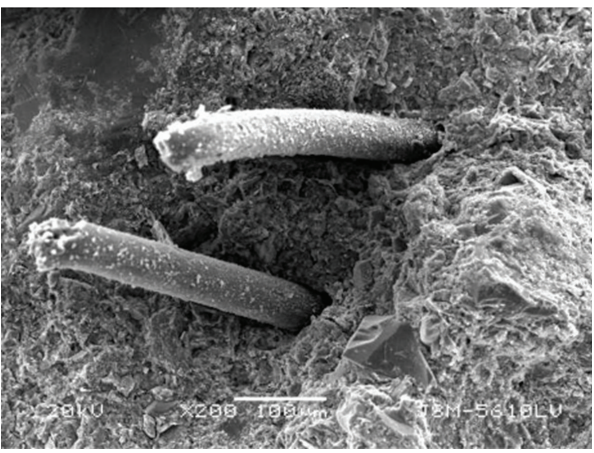

(a)

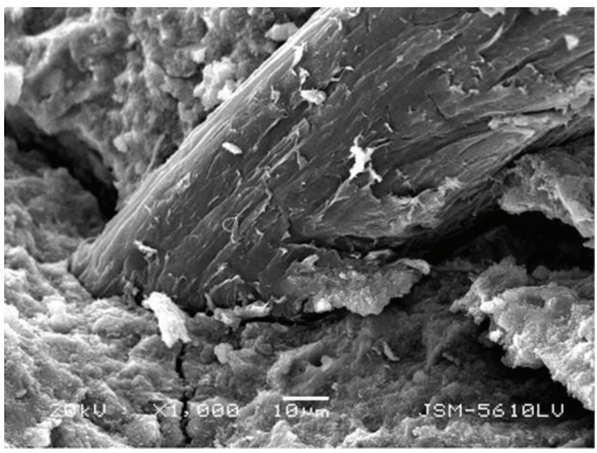

(b)

FIGURE 13: SEM images of polymer and fiber modified cement concrete $((a) \times 200$; (b) $\times 1000)$.

still left in the concrete. The fibers show long length out from the fracture surface and there are some cement hydrate sticks on the surface of the fiber.

Figure 13 shows the SEM image of fracture surface of FSMC. From the images, there is no black hole left by the fiber pull out from the concrete, and the fibers that remained on the surface are much shorter than the fibers showed in Figure 12. Figure 13(b) shows the root of polyester fiber. There is no evident defect around the root of fiber, and the polymer modified cement matrix sticks closely to fiber.

Comparing the SEM images of Figures 12 and 13, it can illustrate that the SBR latex modified cement paste can enhance the cohesion between the cement matrix and fiber, reducing the probability that the fibers draw out from the concrete under bending load. For the FSMC after the bending load reaches the max limit, the fibers break and the remaining sections on the fracture surface are much shorter, but the fibers inside FMC are just easy to pull out and leave evident black holes. The break of polyester fibers consumes more fracture energy. So the SBR latex can be considered to improve the bounding between the fibers and cement matrix and have positive effect on the fracture properties of concrete.

\section{Conclusions}

The fracture behaviors and modification mechanism of SBR latex and polyester fiber modified concrete have been investigated. Summaries of the conclusions are stated below:

(1) The fracture properties and homogeneity of concrete modified by the SBR latex and polyester fiber have 
better improvement; its flexural strength, fracture toughness, fracture energy increase by $44.4 \%$, 397.0\%, and $462.8 \%$ comparing to the normal concrete.

(2) SBR latex and polyester fiber both have a little adverse effect on the compressive strength of concrete.

(3) There are no special chemical products found in the SMC, but in the early period the SBR latex has a little retarding effect: it reduces the extent of cement hydration. The process of polymer film formation is faster and earlier than the cement hydration.

(4) Polymer film has the excellent property of water resistance to reduce the water loss in the concrete, and the cement in the SMC has better environment for hydration than the NC at later age.

(5) The polyester fibers in the FMC have poor bond to the cement matrix, and the fibers are easy to draw out from the concrete; the enhancement of fibers is limited.

(6) The SBR latex can improve the bond between the polyester fibers and cement matrix. The bounding enhancement improves the fracture properties of concrete, fracture toughness, and fracture energy significantly.

\section{Competing Interests}

There is no conflict of interests regarding the publication of this paper.

\section{References}

[1] S. Zhong and Z. Chen, "Properties of latex blends and its modified cement mortars," Cement and Concrete Research, vol. 32, no. 10, pp. 1515-1524, 2002.

[2] S. Zhong, M. Shi, and Z. H. Chen, "The AC response of polymercoated mortar specimens," Cement and Concrete Research, vol. 32, no. 6, pp. 983-987, 2002.

[3] W. Shen, L. Shan, T. Zhang, H. Ma, Z. Cai, and H. Shi, "Investigation on polymer-rubber aggregate modified porous concrete," Construction and Building Materials, vol. 38, pp. 667674, 2013.

[4] C. Pellegrino, F. Da Porto, and C. Modena, "Rehabilitation of reinforced concrete axially loaded elements with polymermodified cementicious mortar," Construction and Building Materials, vol. 23, no. 10, pp. 3129-3137, 2009.

[5] D. V. Gemert, L. Czarnecki, M. Maultzsch et al., "Cement concrete and concrete-polymer composites: two merging worlds: a report from 11th ICPIC Congress in Berlin, 2004," Cement and Concrete Composites, vol. 27, no. 9-10, pp. 926-933, 2005.

[6] F. Pacheco-Torgal and S. Jalali, "Sulphuric acid resistance of plain, polymer modified, and fly ash cement concretes," Construction and Building Materials, vol. 23, no. 12, pp. 3485-3491, 2009.

[7] J. Do and Y. Soh, "Performance of polymer-modified selfleveling mortars with high polymer-cement ratio for floor finishing," Cement and Concrete Research, vol. 33, no. 10, pp. 1497-1505, 2003.
[8] R. Ollitrault-Fichet, C. Gauthier, and G. Clamen, "Micro structural aspect in a polymer-modified cement," Cement and Concrete Research, vol. 28, no. 12, pp. 1687-1693, 1998.

[9] R. Wang, X.-G. Li, and P.-M. Wang, "Influence of polymer on cement hydration in SBR-modified cement pastes," Cement and Concrete Research, vol. 36, no. 9, pp. 1744-1751, 2006.

[10] X. Shilang, Fracture Mechanics of Concrete, Science Press, 2001 (Chinese).

[11] G. Appa Rao and B. K. Raghu Prasad, "Fracture energy and softening behavior of high-strength concrete," Cement and Concrete Research, vol. 32, no. 2, pp. 247-252, 2002.

[12] S. P. Shah and A. Carpinteri, "Fracture mechanics test method for concrete," Report of RILEM FMT-89, Chapman \& Hall, London, UK, 1991. 

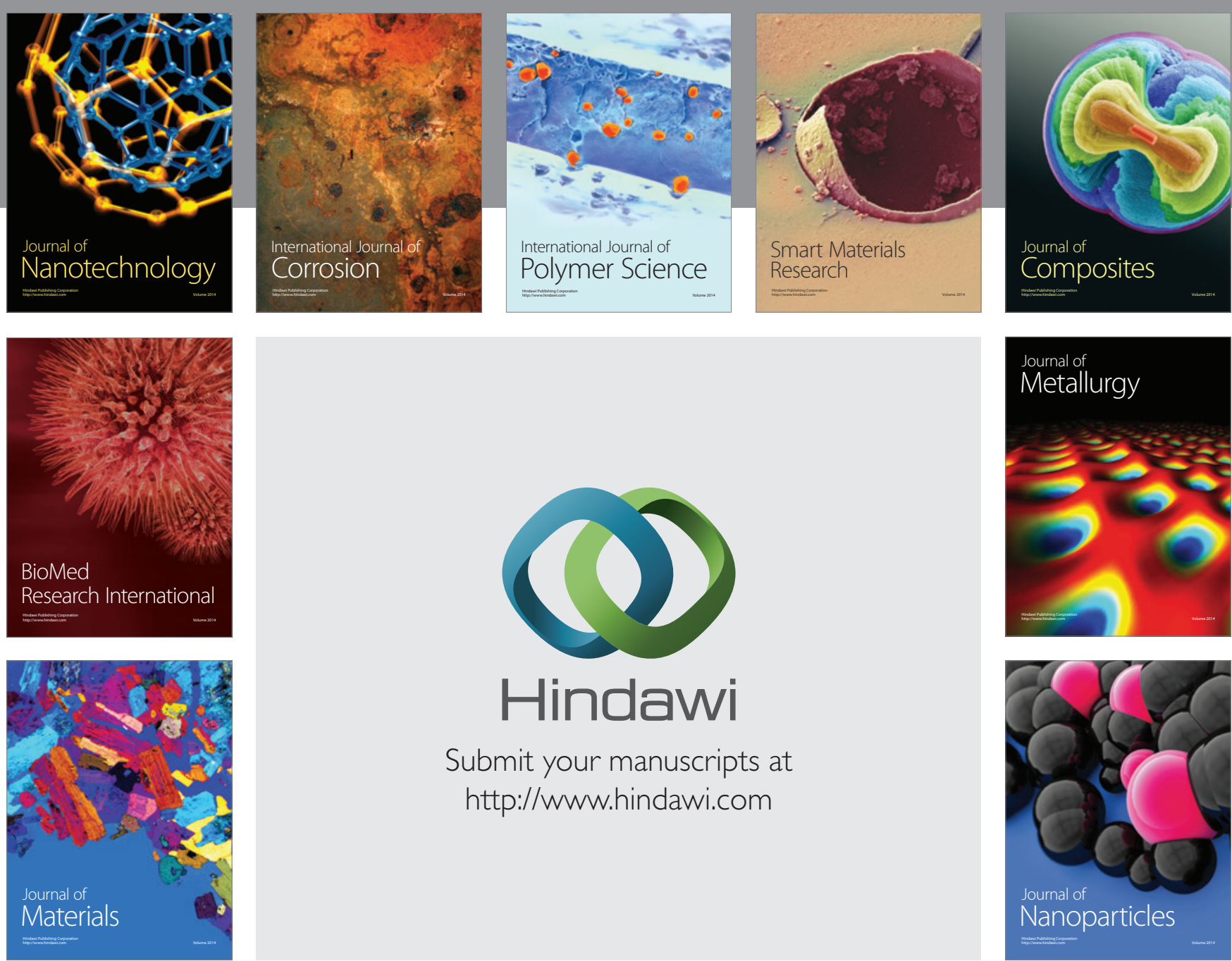

\section{Hindawi}

Submit your manuscripts at

http://www.hindawi.com

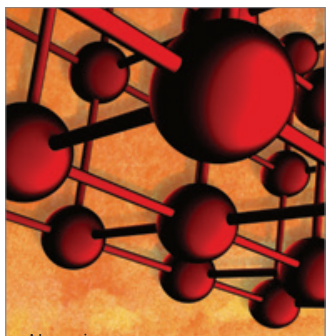

Materials Science and Engineering
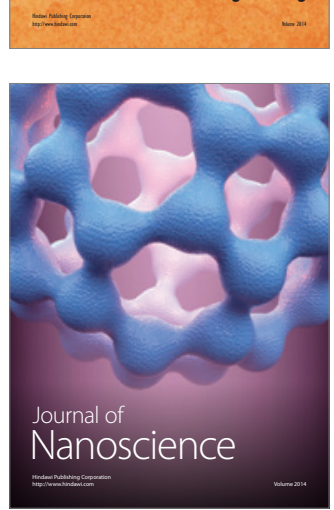
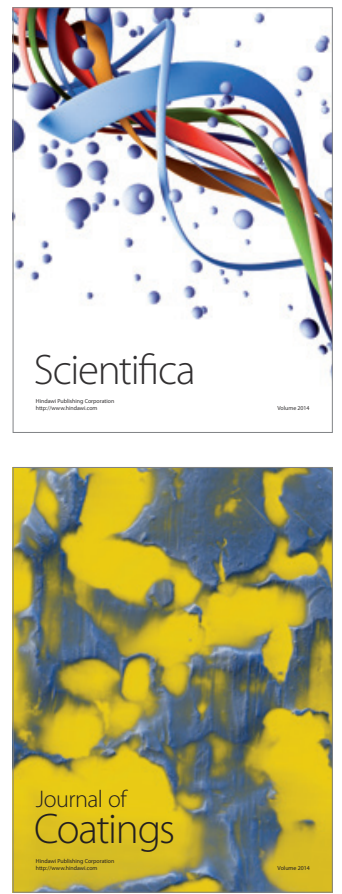
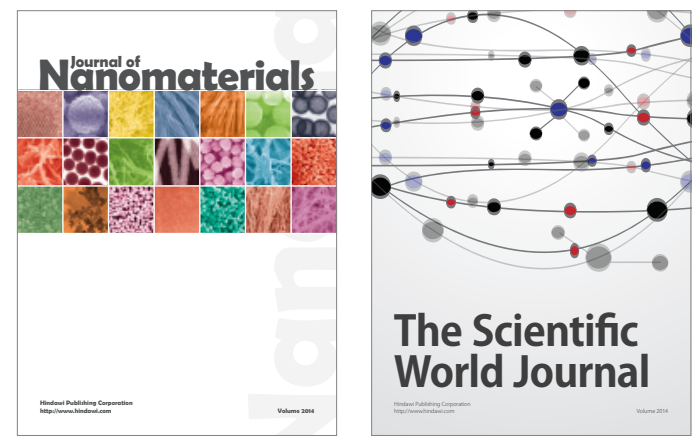

The Scientific World Journal
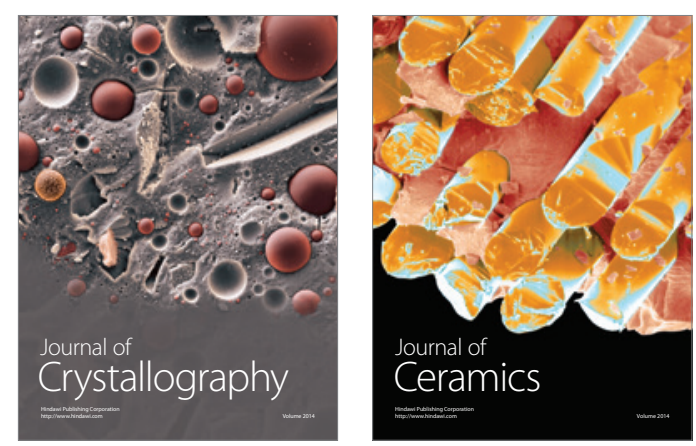
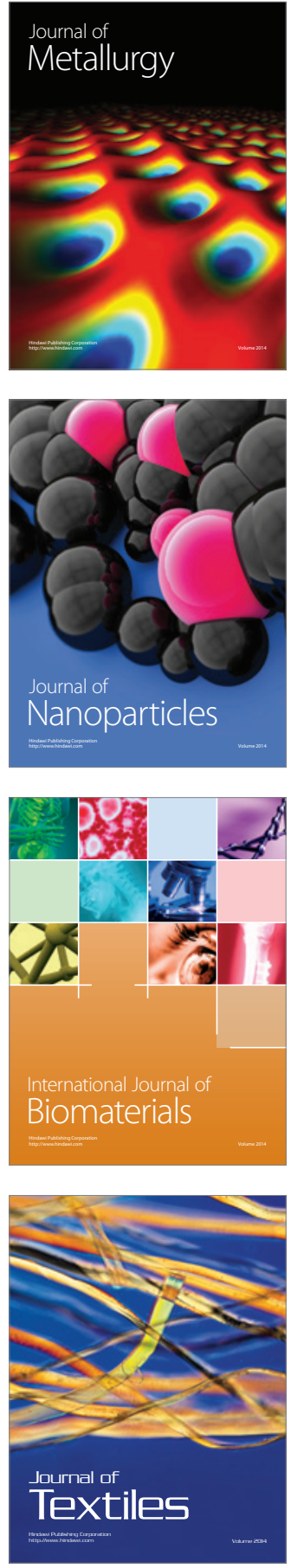